\title{
Short stature and bone structure abnormalities in an 8-year-old girl
}

\author{
Grammatina Boitsios $^{1} \cdot$ Jean-Christophe Le Brun ${ }^{1} \cdot$ Paolo Simoni ${ }^{1}$ \\ Received: 9 February 2018 / Accepted: 9 April 2018 / Published online: 20 April 2018 \\ (C) ISS 2018
}

\section{Answer}

Diagnosis: Pycnodysostosis (also known as osteopetrosis acro-osteolytica)

Pycnodysostosis (also known as osteopetrosis acroosteolytica) is a recessive autosomal disease with a prevalence of one out of 1.7 million individuals [1-4]. Pycnodysostosis, from the ancient Greek $\pi v \kappa \nu o ́ \varsigma$ ("dense, compact, thick") and $\delta v \sigma$ - (abnormal) -ó $\sigma \tau \omega \sigma \iota \varsigma$ (bone development), is an inherited lysosomal disease. Pycnodysostosis along with osteopetrosis, represent the two typical sclerosing bone dysplasia due to the failure of endochondral ossification of the primary spongiosa [4]. Pycnodysostosis is also called the Toulouse-Lautrec's diseases because the French painter has been thought to be affected by pycnodysostosis [3, 5]. Maroteaux first described this disease as osteopetrosis acro-osteolytica because of the association of a multiple areas of bone densification and acroosteolysis [5]. Pycnodysostosis is caused by a mutation of the cathepsin-K gene [2], a papain-like, cysteine protease secreted by osteoclasts into their resorption pit [2]. Cathepsin-K is involved in degradation of type I collagen and other noncollagenous proteins during seventh week of embryogenesis (endochondral ossification of the primary spongiosa). Cathepsin-K deficiency leads to an accumulation of a matrix of calcified cartilage in the cancellous bone [4]. Albeit in patients suffering from pycnodysostosis bone appears increased in density on radiographs, bones are fragile and recurrent fractures (Fig. 2) consequent to a minor trauma with a history of

The case presentation can be found at https://doi.org/10.1007/s00256018-2950-4

Paolo Simoni

paoloemiliosimoni@gmail.com

1 Department of Pediatric Medical Imaging, "Queen Fabiola" Children's University Hospital, Université Libre de Bruxelles, 15 Av. J. J. Crocq, 1020 Brussels, Belgium trauma are common [4-6]. Pycnodysostosis is usually diagnosed during the first years of life because of a work-up for growth failure associated with abnormal skull morphology. Nowadays the diagnosis of pycnodysostosis is confirmed by genetics [4, 6]. In pycnodysostosis, the short stature depends on the shortness of the limbs, while the axial skeleton is usually normal in size [6, 7]. Patients with pycnodysostosis present multiple changes of the skull: frontal, parietal and occipital bossing, delay in sutural closure, hypoplasia, and obtuse mandibular gonial angle (Fig. 3). Other skull abnormalities include midfacial hypoplasia, absent or hypoplastic paranasal sinuses and palate (chronic airway obstruction), teeth growth disturbance, and presence of an excess of Wormian bones in the lambdoid suture [5-9]. Otosclerosis is a rare feature [2]. Clavicle hypoplasia is not constant but is a key imaging finding because these features are not found in osteopetrosis [4]. The vertebral bodies are increased in density but the bone structure of transverse processes is usually normal [4]. Low back pain may be due to a pedicle fracture $[1,4,6]$. Kyphoscoliosis and lumbar hyperlordosis are found in some cases [4]. Hip abnormalities include hip dislocation, coxa valga, and abnormal acetabulum [1]. In the appendicular skeleton, unlike osteopetrosis, the medullary space of the long bones is usually still visible on radiographs. Hands and feet are short and increased in diameter with pointed finger tufts. Nevertheless, the acro-osteolysis of the hands is the most distinctive finding in pycnodysostosis along with the cancellous bone structure abnormalities [6] (Fig. 1). The brachymesophalangy of the fifth finger has also been reported as a specific finding in pycnodysostosis [10]. The differential diagnosis includes mainly the osteopetrosis and to a lesser extent the cleidocranian dysostosis. Even if no treatment is available for pycnodysostosis, the prognosis is favorable. Imaging is useful in the follow-up for the low healing fractures and to detect spine fracture in case of back pain.

\section{Compliance with ethical standards}


Conflict of interest The authors declare that they have no conflicts of interest.

\section{References}

1. Genin G. Anomalies osseuses constitutionnelles. Montpelier: Sauramps Médical; 2008.

2. Huang X, Qi X, Li M, Wang O, Jiang Y, Xing X, et al. A mutation in CTSK gene in an autosomal recessive pycnodysostosis family of Chinese origin. Calcif Tissue Int. 2015;96:373-8.

3. Andren L, Dymling JF, Hogeman KE, Wendeberg B. Osteopetrosis acro-osteolytica. A syndrome of osteopetrosis, acro-osteolysis and open sutures of the skull. Acta Chir Scand. 1962;124:496-507.

4. Boulet C, Madani H, Lenchik L, Vanhoenacker F, Amalnath DS, de Mey J, et al. Sclerosing bone dysplasias: genetic, clinical and radiology update of hereditary and non-hereditary disorders. Br J Radiol. 2016;89:20150349.

5. Maroteaux P, Lamy M. Pyknodysostosis. Presse Med. 1962;70: 999-1002.

6. Maroteaux P, Le Merrer M. Maladies osseuses de l'enfant. 4ème. Paris: Flammarion Médecine-Sciences; 2002.

7. Turan S. Current research on pycnodysostosis. Intractable Rare Dis Res. 2014;3:91-3.

8. Alves N, Cantín M. Clinical and radiographic maxillofacial features of pycnodysostosis. Int J Clin Exp Med. 2014;7:492-6.

9. Bertola D, Amaral C, Kim C, Albano L, Aguena M, Passos-Bueno MR. Craniosynostosis in pycnodysostosis: broadening the spectrum of the cranial flat bone abnormalities. Am J Med Genet A. 2010;152A:2599-603.

10. Laub D, editor. Congenital Anomalies of the Upper Extremity: Etiology and Management [Internet]. Springer US; 2015. Available from: //www.springer.com/gp/book/9781489975034 [cited 2018 Mar 21]. 